\title{
CINE ROMÁNTICO Y GÉNERO: HACIA UNA \\ CINE ROMÁNTICO Y GENERO: HACIA UNA DECONSTRUCCIÓN DE LOS MODELOS TRADICIONALES DE RELACIONES DE PAREJA
}

Beatriz Morales Romo ${ }^{1}$

Resumen: El presente trabajo analiza el cine como medio transmisor de ideologías y divulgador de valores. Más concretamente, se centra en el cine romántico para determinar si este género cinematográfico reproduce una visión tradicional de las relaciones entre hombres y mujeres o, por el contrario, ofrece una visión alternativa y más igualitaria. La metodología empleada se sustenta en tres técnicas: una encuesta aplicada a una muestra de 251 jóvenes universitarios, entrevistas personales realizadas a 6 profesionales expertos en género e igualdad $\mathrm{y}$, por último, el análisis de las 20 películas más taquilleras de género romántico de la primera década del siglo XXI, a través de fichas de análisis. Los resultados obtenidos orientan hacia el reflejo de relaciones amorosas en el cine romántico que no siempre obedecen a patrones fijos, sino que combinan elementos tradicionales y estereotipados con otros alternativos y más igualitarios. La investigación realizada permite señalar al cine como un potente medio transmisor de valores e ideologías y evidencia una lenta evolución hacia mayores de cotas de igualdad en las relaciones de pareja. Los elementos que han sostenido las relaciones de pareja occidentales vinculados a un modelo tradicional siguen muy presentes. En consecuencia, aunque la industria cinematográfica previsiblemente seguirá desterrando ciertos roles y estereotipos de género, -como lo ha venido haciendo en los últimos años-, resulta necesario que, desde el ámbito educativo, se fomenten actitudes igualitarias y para ello, se sugiere el cine como instrumento.

Palabras-clave: Género. Igualdad. Cine. Feminismo. Educación

\begin{abstract}
The present work analyzes the way that cinema transmits ideologies and values. More specifically, it focuses on romantic cinema to determine whether this film genre reproduces a traditional
\end{abstract}

\footnotetext{
${ }^{1}$ Profesor Colaborador. Dpto. Escuela, familia y sociedad. Universidad Internacional de Andalucía.
} 
view of the relations between men and women or, in contrast, offers an alternative and more egalitarian view. The methodology used is based on three techniques: a survey applied to a sample of 251 university students, personal interviews with 6 experts in gender and equality, and finally, an analysis of the 20 highest grossing romantic films in the first decade of the $21^{\text {st }}$ century employing analysis tables. The results obtained point to couple relationships in romantic movies that do not always follow fixed patterns, but combine traditional and stereotyped elements with alternative and more egalitarian ones. The research carried out portrays the cinema as a powerful medium for transmitting values and ideologies and also shows a slow evolution towards greater equality in the relationships between men and women. The elements that have sustained couple relationships in the western world linked to a traditional model are still very common. Consequently, although the film industry will foreseeably continue to reduce certain gender roles and stereotypes - as it has been doing in recent years - it is necessary to promote egalitarian attitudes with education, and cinema is suggested as a good instrument for doing so.
Key words: Gender. Equality. Cinema. Feminism. Education

\section{INTRODUCCIÓN}

El cine es un medio de comunicación social que por un lado genera modelos y valores $\mathrm{y}$, por otro, contribuye a reproducirlos (Loscertales y Núñez, 2001). Estas capacidades no han pasado desapercibidas en la literatura internacional e internacional, pues varias investigaciones señalan la importancia del cine como herramienta de utilidad didáctica (Martínez-Salanova， 2002; Pereira y Marín, 2001; Liles, 2007). Algunas concretan sus potencialidades en aspectos educativos específicos como el abordaje de la violencia en las aulas (Sell et al., 2014) o en la educación saludable (Gómez, 2017).

Este trabajo se sitúa en esta línea de estudio profundizando en el cine como divulgador de valores y transmisor de ideologías. Más concretamente, se analiza el cine romántico para establecer si ofrece una visión tradicional o alternativa de las relaciones entre hombres y mujeres. Por consiguiente, en el trasfondo del estudio se encuentra la perspectiva de género. El objetivo es determinar si el cine ofrece representaciones que orientan en pro de 
la igualdad entre géneros 0 , por el contrario, contribuye a la reproducción de visiones desigualitarias basadas en premisas patriarcales.

Existen trabajos que se han interesado por el cine y la mujer en la época de la posguerra (Ballesteros, 1999; Gómez, 2002) o en la transición española (Castro, 2009; Guarinos, 2009), pero no abundan los estudios que tengan como espacio temporal el siglo XXI. Salvo alguna excepción que se centra en colectivos como el de mujeres inmigrantes (Argote, 2003; Gordillo Álvarez, 2007) hay un importante campo por explorar en el cine más actual desde la perspectiva de género.

Este trabajo expondrá, en primer lugar, el cine romántico como género cinematográfico para conocer sus orígenes y características y, posteriormente, se orientará hacia una configuración de las relaciones de pareja tradicionales o alternativas con vistas a realizar un punto de partida sólido que permita contextualizar los resultados obtenidos.

\section{EL CINE ROMÁNTICO COMO GÉNERO CINEMATOGRÁFICO}

Para Pascual Hernández (2016) la idea occidental del "amor romántico" ha sido empleada para perpetuar un sistema social patriarcal basado en la desigualdad entre hombres y mujeres.

Tomando como fuente a Lema y Vigil (2003), señalamos que en occidente la fantasía acerca del romance es un fenómeno relativamente reciente y que, hasta entrado el siglo XIX, estaba destinado con frecuencia a grupos sociales privilegiados. Sólo en el siglo XX se extendió a la cultura de masas sobre todo en el cine y en la música popular, y de ese modo se trasladó el mito del romance a todas las clases sociales. He aquí un claro ejemplo de la influencia social del cine.

Lapsley y Westlake (1992) analizaron las características del género romántico fundamentalmente a través del análisis y a la discusión de dos elementos: la configuración de figuras que enmascaran las carencias "del otro" y la estructura de la narración romántica. Afirman que las mujeres en Hollywood estaban aleccionadas sobre todo en términos de fantasía masculina. Esto no quiere decir que las estrellas femeninas funcionen únicamente como objetos para la mirada masculina puesto que la relación de los espectadores con la fantasía es más compleja que todo eso. Los espectadores masculinos y la audiencia femenina no se identifican 
sólo con los personajes de sus respectivos géneros, más bien se identifican con las figuras incorporadas en determinados escenarios de fantasía.

Una actriz que interpreta el papel de "la femme fatal" puede convertirse en un punto de identificación tanto para mujeres como para hombres. Un film clásico del género romántico: "Pretty Woman" representa, a través de su protagonista, una mirada voyeurística, dirigida a los espectadores tanto masculinos como femeninos, es decir, constituye un elemento de identificación para los espectadores de ambos sexos.

La línea que siguen los procesos de identificación se corresponde con la de numerosos teóricos, entre ellos Rodowick (1991), Cowie (1997) y Kaplan (1997), quienes en sus respectivos trabajos consideraban la identificación en el cine como un proceso múltiple y disperso, ya que ambos sexos pasan por identificaciones que cruzan los límites de definición de sus propios géneros sexuales; un hecho que reconocen algunos de los jóvenes entrevistados en nuestro trabajo, puesto que se identifican con géneros sexuales opuestos al propio, aunque lo reconozcan solo unos pocos.

Por tanto, podemos concluir que las narraciones románticas se interesan o se refieren de forma casi invariable a los obstáculos hallados en el camino a la realización de un objetivo. Uno de los aspectos centrales de este tipo de narraciones cinematográficas es que parecen buscar la relación sexual, no obstante, el cine no la muestra abiertamente, sino que la historia gira en torno a obstáculos que evitan y retrasan el encuentro sexual y/o afectivo.

Steve Neale (1992) enumera cuatro características principales del romance hollywoodiense: la neurosis y la excentricidad e uno o ambos miembros de la pareja, de forma que se irán curando progresivamente debido al contacto con el otro miembro de la pareja que lo liberara de su excentricidad; el cambio inevitable que un personaje induce en el otro; la constante evocación y encorsetamiento en los signos y valores propios del romance "pasado de moda" y la tendencia a impedir la independencia femenina, o las amenazas de independencia.

En la segunda mitad del siglo $\mathrm{XX}$, el cine aseguró que las protagonistas femeninas tuvieran roles femeninos tradicionales, muy en la línea de las series televisivas del momento. En las comedias románticas más actuales de comienzos del siglo XXI, ya encontramos algunos ejemplos de 
mujeres independientes que se incorporan al mundo laboral, aunque mantienen su ideal por casarse, formar una familia o encontrar al hombre ideal.

Podemos apuntar, a modo de idea general que una gran parte de los esquemas de las comedias románticas modernas son básicamente afirmaciones de los ideales del matrimonio monógamo y de la feminidad doméstica. Ideales que ya estaban presentes en la temprana tradición de las novelas del siglo XIX y hoy en día continúan presentes en la mayor parte de las comedias románticas.

Pascual Fernández (2016) mantiene que la conceptualización del amor en la cultura occidental ha influido en la educación y vida de las mujeres a lo largo de la historia, al tiempo que ha contribuido a reproducir un sistema social basado en el patriarcado que fomenta la desigualdad entre hombres y mujeres.

\section{VISIÓN TRADICIONAL DE LAS RELACIONES DE PAREJA EN EL CINE ROMÁNTICO.}

El cine está fuertemente ligado a cuestiones sociales e históricas, por ello, ha ido evolucionando en función de los cambios sociales. Según Morales (2017) la evolución de los medios de comunicación en los últimos lustros ha dado muestra de su gran potencial de desarrollo social y cultural.

Por otra parte, para Giddens (1991) los valores se disponen en una jerarquía y se sitúan en un continuo desde el polo positivo al negativo, y varían según contextos históricos $\mathrm{y}$ culturales. Dentro de este continuo se sitúan también las relaciones de pareja que oscilan entre un modelo tradicional y un modelo alternativo.

Se especifican a continuación, muy brevemente, algunas de las ideas que han venido sustentando los cimientos de las relaciones de pareja en sociedades occidentales y que se corresponden con un modelo tradicional. En primer lugar la pareja como centro organizativo de la vida cotidiana. La pareja es normativa y constituye un elemento clave en las relaciones afectivas (Esteban, 2011). También es clave el modelo heteronormativo por excelencia, entendido como una forma dicotómica entre hombres y mujeres con un componente de obligatoriedad social. Otro patrón común es la relevancia del atractivo sexual. Para Illouz (2012) la identidad de género, especialmente la de las mujeres está muy vinculada a la identidad sexual a través de la legitimación normativa de la sexualidad 
y del consumismo. El cuarto elemento es la complementariedad de la persona adecuada, como consecuencia de las transformaciones de la época moderna. Estos cambios sociales han dado lugar a conceptos como el amor empresarial acuñado por Illouz (2009), para enfatizar el paralelismo entre los valores considerado para la elección de candidatos para un puesto laboral y la elección de pareja. A pesar del incremento de la tasa de divorcios en las sociedades posmodernas, la durabilidad de la pareja y el consecuente aporte de estabilidad siguen estando como trasfondo. $\mathrm{Y}$, finalmente el matrimonio vinculado al amor. Según Onfray (2002), el modelo de amor occidental se basa en cuatro premisas directamente relacionadas con el matrimonio: monogamia, fidelidad, procreación y cohabitación.

Ciertamente no todos estos elementos son preceptivos en una relación de pareja, pero entre todos constituyen el imaginario social de una visión muy extendida del ideal de relación amorosa. En los últimos lustros, de la mano de la evolución hacia una igualdad de género efectiva entre hombre y mujeres, se han producido cambios en todos los órdenes sociales que han visto también su reflejo en las relaciones afectivas de pareja. El cine ha ido recogiendo de forma progresiva, y a veces ralentizada, cambios como relaciones de pareja homosexuales en films como Philadelphia (1993) o Brokeback Mountain (2005) o el poliamor (esencia de films como Drei del año 2010 y la española Vicky Cristina Barcelona del año 2008).

El género cinematográfico es considerado un fuerte transmisor de valores, y son numerosos los trabajos que hablan de su utilidad didáctica (Sell et al., 2014; Blasco et al., 2015; Mangot and Vasantmeghna, 2017), tomando como base la influencia que ejercen en los espectadores. Por tanto, resulta relevante analizar las imágenes que el cine transmite sobre distintas cuestiones sociales en general y sobre las relaciones de pareja en particular.

Según Almacellas (2004) las obras cinematográficas resultan ser un punto de partida común desde el cual las personas pueden dialogar y repensar sus propias historias, permitiendo la construcción de identidades individuales y colectivas. Esta potencialidad pone de relieve la importancia de que el cine ofrezca imágenes de relaciones de pareja igualitarias, que contribuyan a crear una sociedad basada en valores que se 
desmarquen de lastres patriarcales y machistas.

Pero el cine no es una excepción, en la socialización de hombres y mujeres, así como en sus relaciones interpersonales, existen unos valores que imperan y que están ligados al sistema patriarcal (Charkow y Nelson, 2000).

Este artículo pretende profundizar en cómo se muestran las relaciones entre hombres y mujeres en el cine romántico y en las percepciones que tienen los jóvenes universitarios sobre la influencia del cine para, en última instancia, concluir si el cine del género analizado está contribuyendo en los últimos años a divulgar valores más igualitarios o sigue perpetuando relaciones de pareja basadas en un modelo tradicional apoyado en el patriarcado como referencia.

\section{METODOLOGÍA}

Este trabajo trata de dar respuesta a una serie de interrogantes, entre los cuales destaca el análisis del cine romántico como transmisor de actitudes, valores e ideologías, la determinación de si las relaciones de pareja mostradas en los films románticos se corresponden con un modelo tradicional o alternativo y el conocimiento de las percepciones que tienen los jóvenes universitarios sobre el cine en relación a su repercusión

La investigación se ha apoyado en una metodología mixta, tanto cuantitativa (encuesta) como cualitativa (entrevistas personales y análisis fílmico de las películas seleccionadas).

La encuesta fue aplicada a una muestra de 251 estudiantes de titulaciones universitarias vinculadas al ámbito de la Educación (Magisterio y Pedagogía) y al de la Comunicación (Publicidad y Relaciones Públicas) de las ciudades de Salamanca y Ávila.

Los gráficos 1 y 2 informan sobre la composición de la muestra. El primero refleja una clara predominancia del sexo femenino respecto del masculino. Por ello, se trabajará con los datos relativos, esto es con porcentajes en lugar de con valores absolutos, aunque ambos se mostrarán en las tablas de contingencia.

El gráfico 2 evidencia también la composición por sexo, esta vez en relación a cada uno de los tres centros universitarios españoles encuestados. La mayor concentración de estudiantes pertenece a la Escuela Universitaria de Educación y Turismo de Ávila, seguida de la Facultad de Comunicación de la 
Universidad Pontificia de Salamanca (de Educación de Salamanca.

titularidad privada) y de la Facultad de

Gráfico 1. Sexo de los encuestados.

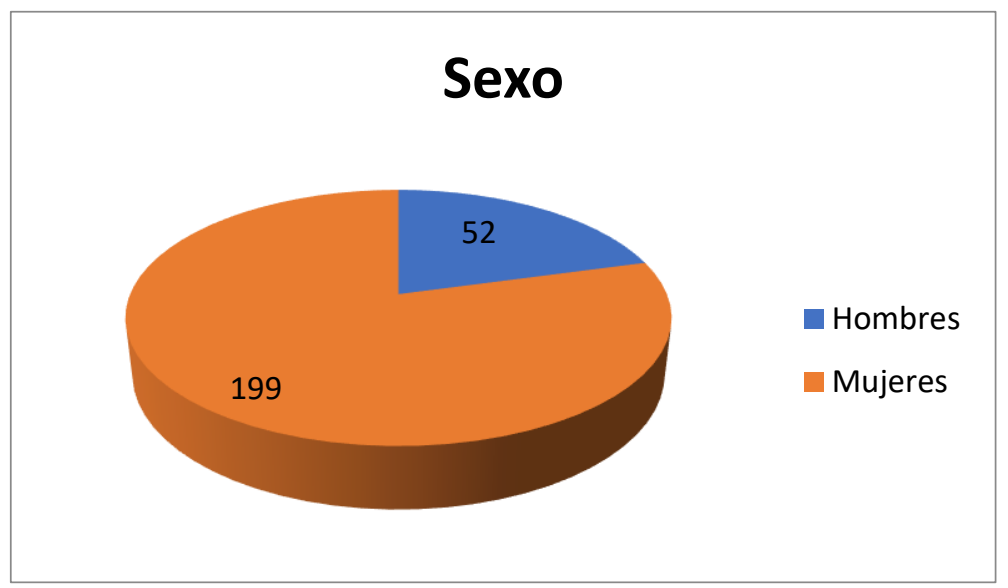

Gráfico 2. Titulación de los universitarios encuestados

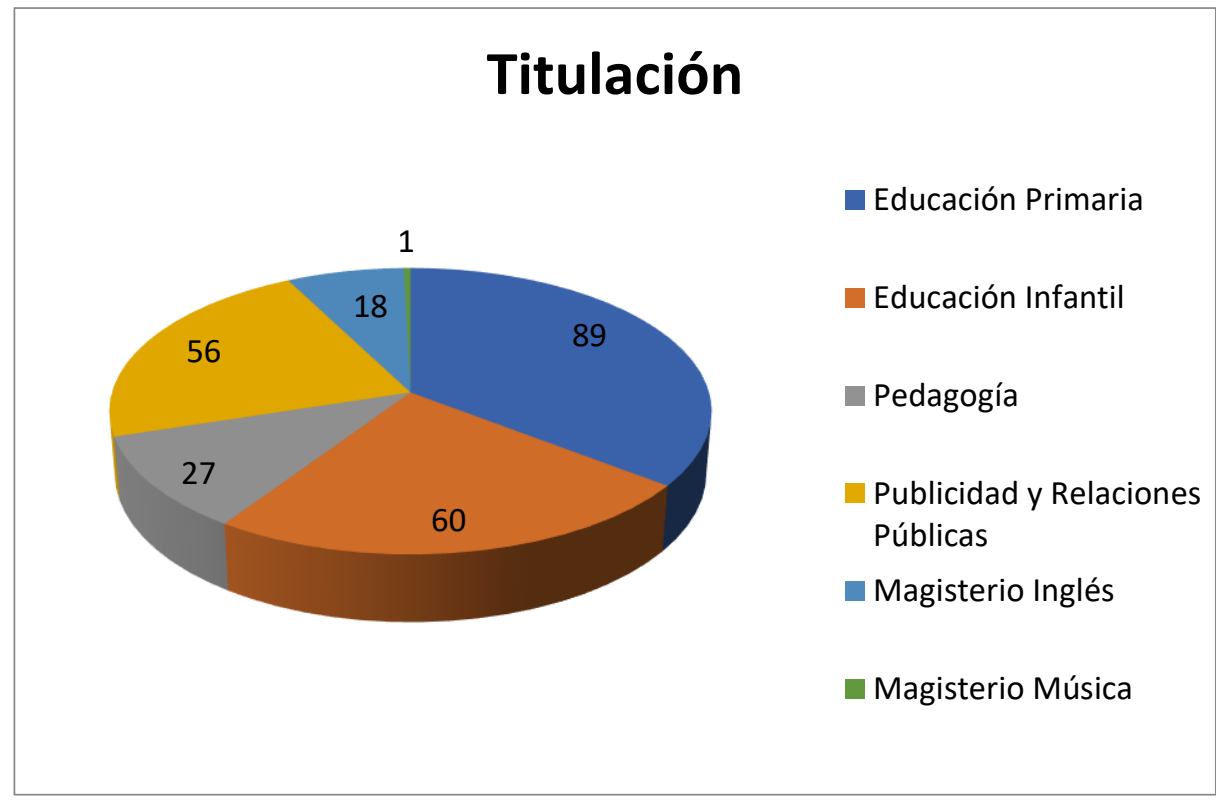

Dentro de la parte cualitativa, se han llevado a cabo 6 entrevistas personales a diversos profesionales del campo de la educación, comunicación, expertos en género e igualdad que han sido seleccionados por ser sujetos portadores de significados para aportar sus conocimientos acerca del tema que nos ocupa.

Los

profesionales seleccionados ostentan los siguientes perfiles:

E1: Profesora titular de Comunicación Audiovisual de universidad española, 52 años. 
E2: Profesor titular del área de Filología en universidad española, 45 años.

E3: Profesora Catedrática del Master de Estudios Interdisciplinares de Género., 59 años.

E4: Profesor Contratado Doctor del área de Comunicación de facultad española, 47 años.

E5: Licenciada en Ciencias de la Educación Física y del Deporte y alumna del doctorado de Estudios Interdisciplinares de Género en universidad española, 28 años.

E6: Profesor del Master de Estudios Interdisciplinares de Género. 36 años.

En cuanto a las películas, se realizó una selección de los veinte films más taquilleros de género romántico producidos entre los años 2000 y 2010. Se trata de los siguientes: Mi gran boda griega; ¿En qué piensan las mujeres?;
Hitch especialista en ligues; Los padres de ella; Sexo en Nueva York I y II; American Pie 2; Como la vida misma; El diablo se viste de Prada; 50 primeras citas; Historias de San Valentín; Todo incluido; Cómo perder a un chico en 10 días; ¿Qué les pasa a los hombres?; Espera al último baile; La cruda realidad; El diario de Noa; Querido John; Chocolat y Cartas para Julieta.

Para su análisis se han utilizado dos tipos de fichas de análisis, cada uno de los cuáles nos ha proporcionado una valiosa información para ser interpretada: ficha descriptiva y ficha de análisis de variables.

La ficha descriptiva pretende ser un primer acercamiento a cada película mostrando aspectos tales como su año de producción, guion, edad para la que está recomendada, etc.

Tabla 1. Ficha de análisis de las relaciones de pareja

\section{Modelo tradicional}

\begin{tabular}{|l|l|}
\hline Sumisión & Manipulación/ engaño \\
\hline Dependencia & Inevitabilidad \\
\hline Violencia & Amor-sufrimiento \\
\hline Maltrato & Celos \\
\hline Ocultación/ infidelidad & Rechazo / miedo \\
\hline
\end{tabular}

\section{Modelo alternativo}

\begin{tabular}{|l|l|}
\hline Amistad & Fidelidad \\
\hline Igualdad & Ternura \\
\hline Amor & Transparencia \\
\hline
\end{tabular}


Independencia

Respeto

\section{Compartir}

Diálogo entre iguales
La ficha de análisis de las relaciones se basa en un modelo tradicional basado en estereotipos de género, que es desigualitario y sexista, con una serie de variables con una connotación negativa, mientras que el modelo alternativo está basado en relaciones de igualdad entre los dos miembros de pareja, amistad, respeto y consideración para ambos. La aplicación de estas fichas de relación de pareja a cada película pretende identificar si esta relación se ajusta más a uno u otro modelo a partir de la verificación de la existencia de las distintas variables en la muestra de películas seleccionada.

\section{RESULTADOS}

Según los resultados obtenidos, las diferencias por titulación, por titulación previa, por edad y por centro no han resultado significativas estadísticamente en ninguno de los ítems del cuestionario. En cambio, en algunos aspectos el género es una variable que determina diferencias significativas.

\section{EL CINE COMO DIVULGADOR DE VALORES}

Como muestran los datos de la tabla 2, un elevado porcentaje de hombres encuestados (70\%), opina que el cine influye en la socialización de niños y jóvenes "muchas veces", frente al $(55,1 \%)$ de las mujeres. En cambio, hay más mujeres $(16,7 \%)$ que creen esto se produce "siempre", frente a un $6 \%$ de los hombres.

Las diferencias entre sexos no son estadísticamente significativas, se observa una tendencia en ambos sexos a considerar el cine como un potente instrumento divulgador de valores en niños y jóvenes, concretamente un 72,6 $\%$ de ellos.

Tabla 2. El cine como divulgador de valores por sexo

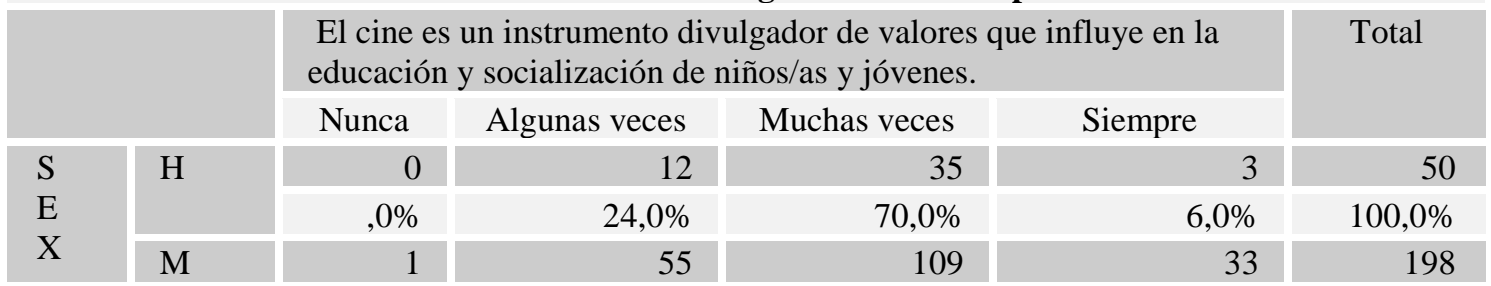




\begin{tabular}{|l|r|r|r|r|r|}
\hline O &, $5 \%$ & $27,8 \%$ & $55,1 \%$ & $16,7 \%$ & $100,0 \%$ \\
\hline Total & 1 & 67 & 144 & 36 & 248 \\
\hline &, $4 \%$ & $27,0 \%$ & $58,1 \%$ & $14,5 \%$ & $100,0 \%$ \\
\hline
\end{tabular}

Los expertos entrevistados se sitúan en la misma línea discursiva, afirmando que el cine es un medio de comunicación social muy potente a la hora de transmitir valores.

Sí, el cine actúa como agente de socialización para la población, especialmente como ya he dicho para los más jóvenes. [E5]

Creo que por encima de la educación. Es un patrón de identificación altísimo. [E3]

\section{EL CINE COMO REFLEJO DE UNA REALIDAD SOCIAL SESGADA.}

La opinión mayoritaria en la encuesta es que el cine ofrece sesgos "algunas veces" o "muchas veces". En este caso se constata que existen diferencias estadísticamente significativas entre sexos (ver tabla 10). Los varones consideran, en mayor porcentaje que las mujeres, que el cine muestra sesgos en su representación de la realidad social.

Tabla 3. El cine como reflejo de una realidad social sesgada

\begin{tabular}{|c|c|c|c|c|c|c|}
\hline & \multicolumn{4}{|c|}{ El cine refleja una realidad social sesgada, tergiversada } & \multirow[t]{2}{*}{ Total } \\
\hline & & Nunca & Algunas veces & Muchas veces & Siempre & \\
\hline \multirow{4}{*}{$\begin{array}{l}S \\
E \\
X \\
O\end{array}$} & \multirow[t]{2}{*}{$\mathrm{H}$} & 0 & 23 & 19 & 8 & 50 \\
\hline & &, $0 \%$ & $46,0 \%$ & $38,0 \%$ & $16,0 \%$ & $100,0 \%$ \\
\hline & \multirow[t]{2}{*}{ M } & 2 & 122 & 70 & 3 & 197 \\
\hline & & $1,0 \%$ & $61,9 \%$ & $35,5 \%$ & $1,5 \%$ & $100,0 \%$ \\
\hline \multirow{2}{*}{\multicolumn{2}{|c|}{ Total }} & 2 & 145 & 89 & 11 & 247 \\
\hline & &, $8 \%$ & $58,7 \%$ & $36,0 \%$ & $4,5 \%$ & $100,0 \%$ \\
\hline
\end{tabular}

En este mismo sentido, los

sujetos entrevistados son muy contundentes a la hora de afirmar que el cine romántico muestra una realidad muy sesgada e incluso tergiversada.

Una película es ficción y no refleja una realidad verdadera. Reflejan un amor pasional, poco racional y sin límites. Además, de reproducir papeles estereotipados que limitan el comportamiento de la mujer y el hombre dentro de una relación. La realidad es mucho más amplia en el que no hay un guion para cada sexo. [E5] 
Además, añaden que este sesgo

está, a su vez, relacionado con

idealizaciones que están en el imaginario social sobre relaciones de pareja, la familia, etc.

\section{EL CINE COMO REFLEJO DE}

\section{ACTITUDES Y VALORES DEL MUNDO REAL.}

A la hora de valorar el cine como reflejo de actitudes y valores de la vida cotidiana, hay grandes similitudes entre hombres y mujeres. Ambos centralizan sus opiniones entre "algunas" y "muchas veces", concentrando el primer valor casi el doble de respuestas (tabla 4).

\begin{tabular}{|l|r|r|r|r|r|r|}
\hline \multicolumn{2}{|c|}{ Tabla 4. El cine como reflejo de actitudes y valores del mundo real. } \\
\hline \\
\hline
\end{tabular}

Los entrevistados tienen una visión más escéptica al respecto:

Una película es ficción y no refleja una realidad verdadera. Reflejan un amor pasional, poco racional y sin límites, además de reproducir papeles estereotipados que limitan el comportamiento de la mujer y el hombre dentro de una relación. La realidad es mucho más amplia en la que no hay un guion para cada sexo. [E5]
La argumentación común que podemos extraer es que en las películas de género romántico se muestran las relaciones amorosas como idílicas y alejadas de la realidad.

Muestra una realidad
edulcorada, a veces
exagerada y casi siempre
limitada, de lo que significa
el amory lo que se espera de
una relación. [E4]

Es preciso señalar que los profesionales entrevistados no sitúan al género romántico entre sus preferencias 
$y$, en la mayoría de las entrevistas, se percibe una cierta connotación negativa hacia sus contenidos y estructura.

\section{EL CINE COMO TRANSMISOR DE IDEOLOGÍAS Y VALORES SOCIALMENTE APROPIADOS.}

Al valorar si el cine tendría que contribuir a transmitir ideologías y valores socialmente apropiados, hay más mujeres $(36 \%)$ que hombres (16\%) que creen que esto "siempre" debería ocurrir. Es posible que estos datos estén relacionados con una mayor sensibilidad de las mujeres ante los temas de transmisión educativa de valores que recogen algunas investigaciones (Hernández Mercedes, 2000).

Tabla 5. El cine como transmisor de ideologías y valores socialmente apropiados.

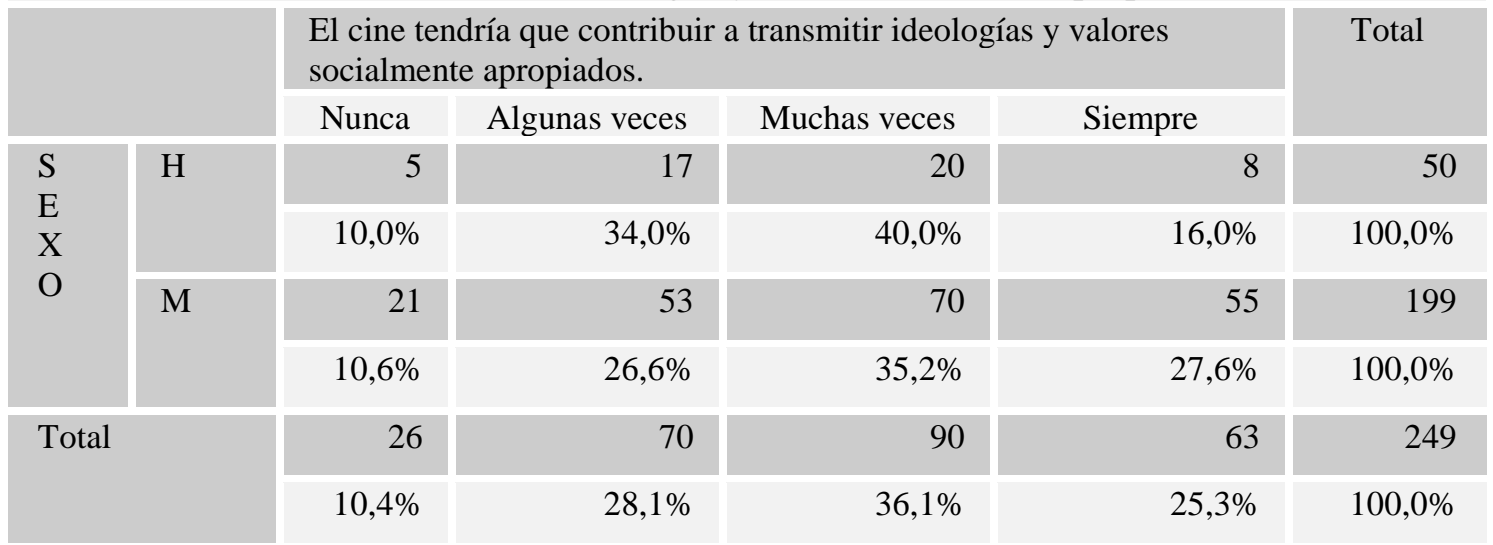

Por su parte, los expertos presentan una actitud ambivalente en este aspecto. Coinciden en su potencial como transmisor de ideologías, aunque consideran que en ocasiones transmite ideologías inadecuadas que reproducen estereotipos o falsas creencias.

La relación del cine con la realidad es muy compleja. Toda ficción tiene que ser sesgada y tergiversada. No recuerdo quién dijo algo como que el melodrama es una realidad despojada de todos sus aspectos más aburridos. El cine romántico falsea la realidad pero, al mismo tiempo, se dirige a las fantasías "verdaderas" de la sociedad. [E2]

También apuntan a una evolución positiva en los últimos años, en los que es posible encontrar películas que reflejan relaciones de pareja más igualitarias, con roles menos estereotipados en función del género, 
relaciones no heteronormativas, etc.

\section{IDENTIFICACIÓN}

CON

\section{PERSONAJES DEL CINE.}

La opinión de los encuestados sobre el ítem: "me siento identificado con personajes del cine", revela que hay más hombres que no se identifican (28\%) frente a un 10,6\% de mujeres. El 63,3\% de mujeres se siente identificado "algunas veces", frente a un $42 \%$ de los hombres. Las diferencias entre hombres y mujeres son estadísticamente significativas en este ítem (ver tabla 11).

Tabla 6. Identificación con personajes del cine

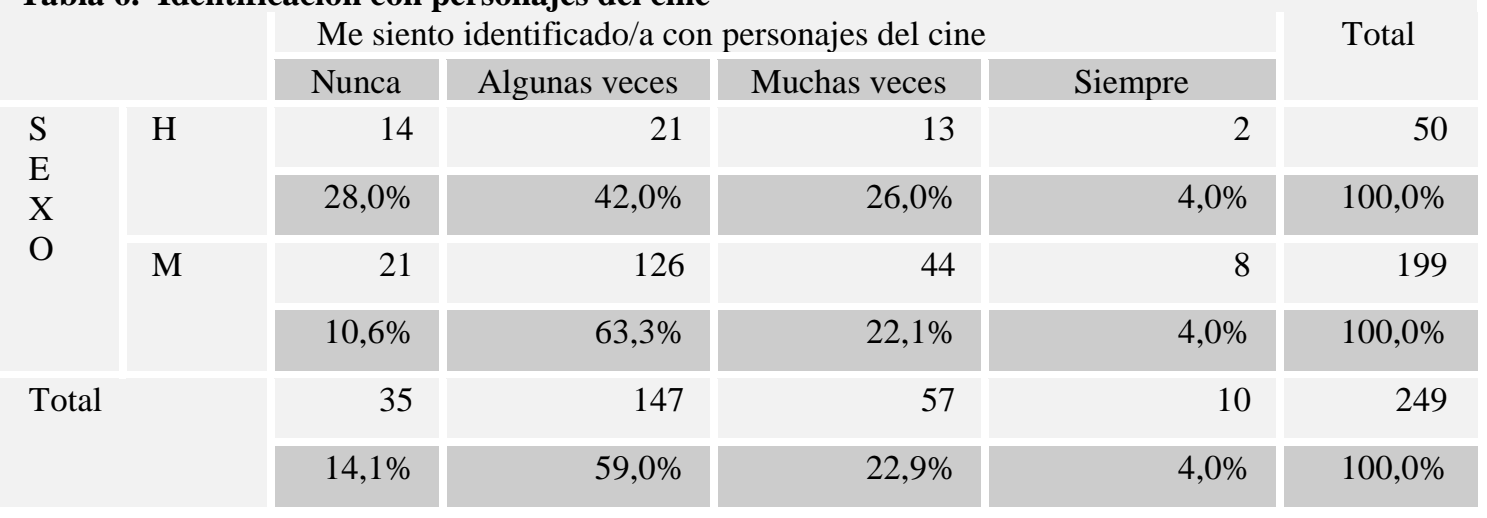

En las fichas empleadas se ha evidenciado que hay una gran diversidad de hombres y mujeres protagonistas, pero todos ellos suelen tener como común denominador su búsqueda del amor como camino hacia la felicidad. Este último elemento, sería lo que favorece la identificación con los personajes, aunque el perfil del protagonista difiera del espectador $\mathrm{o}$ espectadora.

Los profesionales entrevistados no han llegado a un consenso sobre si el cine romántico está más dirigido a un género que a otro, aunque todos coinciden en los peligros que tiene la identificación de los espectadores con personajes de la gran pantalla que representan modelos idealizados $\mathrm{y}$ alejados de la realidad.

Las películas de este género presentan esquemas narrativos repetitivos y sus personajes suelen estar mиy estereotipados. [E4]

Una buena parte de los estudiantes universitarios encuestados, en la pregunta abierta referida a su valoración de las relaciones de pareja 
mostradas en el cine, muestran una visión crítica respecto a sus representaciones idealizadas.

En el cine romántico suelen aparecer personajes idílicos que no existen en realidad. Con frecuencia hacen historias perfectas $y$ modélicas para captar la atención de los oyentes y que se interesen por ello. [C10]

\section{EL CINE ROMÁNTICO Y LA VISIÓN CONSERVADORA DE LA}

\section{MUJER}

Ante la consideración de que el cine romántico muestra una visión tradicional/ conservadora de la mujer, la mitad de la muestra considera que lo hace "algunas veces" y casi la otra mitad se posiciona entre "muchas veces" y "siempre". No resulta significativa la diferencia por sexo.

Tabla 7. El cine romántico muestra una visión conservadora de la mujer

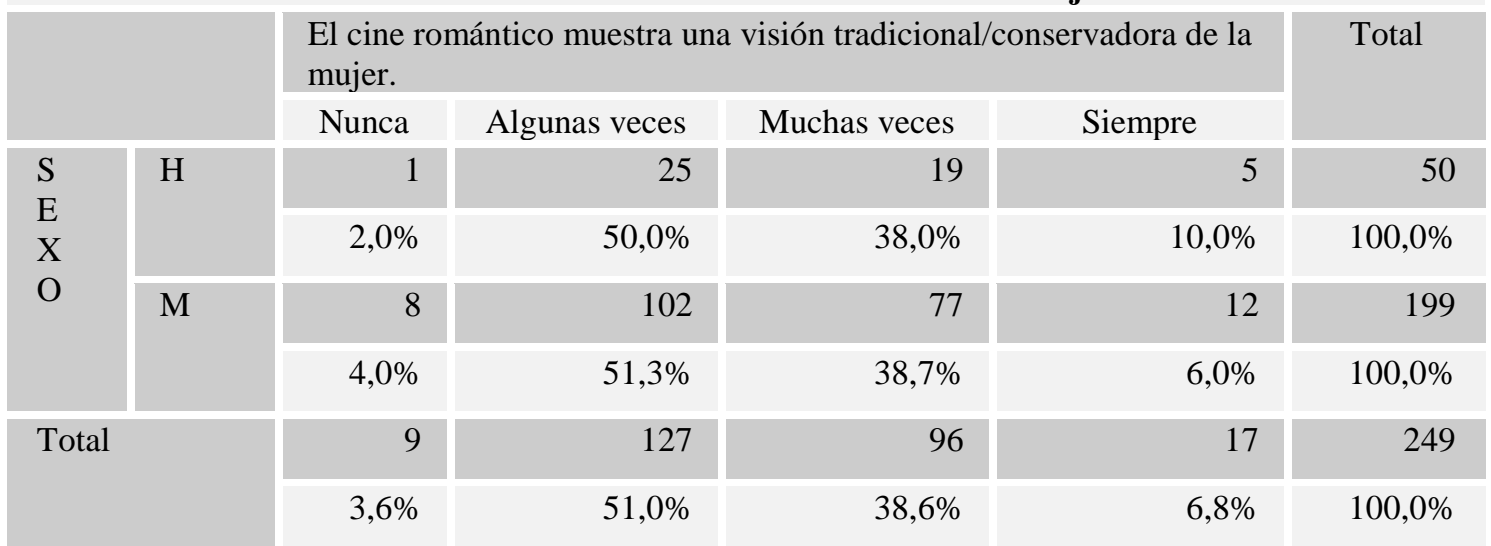

Los expertos consultados lo tienen claro: el cine romántico muestra una visión tradicional y conservadora de la mujer, aunque apuntan a una evolución hacia una construcción más igualitaria que incorpora nuevos elementos que orientan hacia relaciones más equitativas.

En rasgos generales, sí. Porque la mujer y el hombre siguen apareciendo en polos opuestos en las formas de ser $y$ hacer marcando lo que es correcto o no para uno u otra respectivamente. [E5]

En las películas analizadas se ha verificado que cohabitan mujeres soñadoras y románticas con otras fuertes, valientes y con capacidad de liderazgo (rasgos típicamente masculinos).

\section{EL CINE ROMÁNTICO Y LA VISIÓN CONSERVADORA DEL HOMBRE}

En el caso de los hombres, los 
resultados obtenidos son similares a los

recogidos para las mujeres, aunque con

pequeñas diferencias porcentuales que apuntan hacia un reflejo ligeramente menos conservador de ellos respecto de ellas (tabla 8).

Tabla 8. El cine romántico muestra de una visión conservadora del hombre

\begin{tabular}{|c|c|c|c|c|c|c|}
\hline & \multicolumn{4}{|c|}{ El cine romántico muestra una visión tradicional/conservadora del hombre } & \multirow[t]{2}{*}{ Total } \\
\hline & & Nunca & Algunas veces & Muchas veces & Siempre & \\
\hline \multirow{4}{*}{$\begin{array}{l}S \\
E \\
X \\
O\end{array}$} & \multirow[t]{2}{*}{$\mathrm{H}$} & 2 & 28 & 17 & 3 & 50 \\
\hline & & $4,0 \%$ & $56,0 \%$ & $34,0 \%$ & $6,0 \%$ & $100,0 \%$ \\
\hline & \multirow[t]{2}{*}{ M } & 16 & 113 & 62 & 7 & 198 \\
\hline & & $8,1 \%$ & $57,1 \%$ & $31,3 \%$ & $3,5 \%$ & $100,0 \%$ \\
\hline \multirow{2}{*}{\multicolumn{2}{|c|}{ Total }} & 18 & 141 & 79 & 10 & 248 \\
\hline & & $7,3 \%$ & $56,9 \%$ & $31,9 \%$ & $4,0 \%$ & $100,0 \%$ \\
\hline
\end{tabular}

Varios de los sujetos realizaban las siguientes conceptualizaciones sobre el rol del hombre en el cine:

El hombre... el fuerte, el valeroso (...), el que trae el alimento, la comida a la casa, o sea él trabaja fuera y ella está en casa..., porque la labor de casa no se considera trabajo nunca. [E1]

El hombre suele ser silencioso y estoico pero con mucha vida interior y en la comedia es encantadoramente torpe. No creo que los patrones cambien mucho con las mujeres aunque siempre suelen aparecer como mucho más generosas y sacrificadas. Son ellas las que terminan "salvando" al hombre. [E2]

En el discurso de los entrevistados subyace la idea de que los patrones de hombres y mujeres siguen estando claramente diferenciados en el cine romántico, además de estereotipados. Vinculan esta realidad con patrones culturales y con el reflejo de la realidad social.

Es una cosa curiosa, porque la mujer, siempre se dice que se muere por la emoción y el hombre no, la razón: patrones culturales. [E1]

En el análisis de las películas nos encontramos con protagonistas masculinos que se dibujan como personajes férreos con gran determinación y cierta frialdad (que habitualmente va disminuyendo conforme avanza el film), pero también con otros que se muestran sensibles, patosos y hasta sumisos. Por tanto, no existe una visión homogénea del perfil 
de los varones en las películas analizadas.

\section{EL CINE ROMÁNTICO COMO} VISIÓN TRADICIONAL DE LAS RELACIONES ENTRE HOMBRES Y MUJERES.
Un $45,2 \%$ de los universitarios encuestados cree que el cine muestra una visión tradicional de las relaciones entre hombres y mujeres "algunas veces" y un $44,4 \%$ considera que lo hace "muchas veces". Solamente el $4 \%$ de la muestra considera que nunca se muestran visiones conservadoras de las relaciones (tabla 9).

Tabla 9. El cine romántico como visión tradicional de las relaciones entre hombres y mujeres.

\begin{tabular}{|c|c|c|c|c|c|c|}
\hline & & \multicolumn{4}{|c|}{$\begin{array}{l}\text { El cine romántico muestra una visión tradicional/conservadora de } \\
\text { las relaciones entre hombres y mujeres. }\end{array}$} & \multirow[t]{2}{*}{ Total } \\
\hline & & Nunca & Algunas veces & Muchas veces & Siempre & \\
\hline \multirow{4}{*}{$\begin{array}{l}\mathrm{S} \\
\mathrm{E} \\
\mathrm{X} \\
\mathrm{O}\end{array}$} & \multirow[t]{2}{*}{$\mathrm{H}$} & 0 & 22 & 25 & 3 & 50 \\
\hline & &, $0 \%$ & $44,0 \%$ & $50,0 \%$ & $6,0 \%$ & $100,0 \%$ \\
\hline & \multirow[t]{2}{*}{ M } & 10 & 90 & 85 & 13 & 198 \\
\hline & & $5,1 \%$ & $45,5 \%$ & $42,9 \%$ & $6,6 \%$ & $100,0 \%$ \\
\hline \multirow{2}{*}{\multicolumn{2}{|c|}{ Total }} & 10 & 112 & 110 & 16 & 248 \\
\hline & & $4,0 \%$ & $45,2 \%$ & $44,4 \%$ & $6,5 \%$ & $100,0 \%$ \\
\hline
\end{tabular}

Los expertos entrevistados señalan que los roles de hombres $\mathrm{y}$ mujeres parecen estar muy marcados y ligados fuertemente a una visión tradicional de los géneros.

La mujer tiene que ser bella, guapa, tranquila, rodeada de plenas virtudes, etc. etc. ¿para qué? Complacer al hombre... si, si, no por ella mismo sino porque digamos que cuantas más virtudes de ese tipo la mujer reúne será más satisfactoria para los deseos de hombre, el descanso del guerrero y el hombre es un hombre conservador, macho, tutor de la mujer, rodeado de unas virtudes etc., y dominando la sociedad, o sea, que el romanticismo, por supuesto, en lo que yo percibo incluso en la ropa que le colocan a las mujeres, las formas en las que las visten, es una forma invivible, una mujer que lleva esas ropas no puede dedicarse a vivir solo puede dedicarse a llevar esa ropa.... [E3]

Pero de nuevo, se muestran algunas opiniones que marcan un cambio de tendencia en relación a las imágenes 
tradicionales de los roles de género, como el caso que plantea un entrevistado para evidenciar otras opciones de roles que difieren de las tradicionales.

Hay películas, por ejemplo, Broke Back Montain, en las que tradicionalmente no puedes encontrarte eso y no deja de ser género romántico, pero claro el cine avanza también a la misma velocidad que la propia realidad. [E6]

Para mí la clave está, otra vez, en el tipo de amor romántico que se dibuja. Los personajes femeninos se han ido adaptando a los tiempos (son mujeres en el mercado laboral y, desde ese punto de vista, no son modelos tradicionales) pero el mensaje de fondo y el significado del enamoramiento es el mismo de hace años. [E4]

El análisis de las películas revela que, en 9 de las 20 estudiadas, convive el modelo tradicional con el modelo alternativo, en 2 aparece una visión eminentemente tradicional de las relaciones de pareja y en las 9 restantes, las relaciones se enmarcan dentro de un esquema más alternativo, aunque mantiene ciertas dosis de elementos conservadores. Estos datos contrastan con la percepción de los estudiantes universitarios, pero van en la línea de opinión de los expertos que constatan que se han producido cambios en la dirección de mostrar relaciones más igualitarias y menos estereotipadas. A pesar de ello, parece evidente, a tenor de los resultados obtenidos, que se ha producido una evolución en los contenidos y valores que refleja el cine romántico, pero no parece ser suficiente en relación a los cambios sociales que se han producido en los últimos lustros, y los que la sociedad demanda para avanzar en pro de la igualdad.

\section{CONCLUSIONES}

En nuestro acercamiento al cine como transmisor de actitudes, valores e ideologías, los resultados obtenidos por parte de los estudiantes universitarios reflejan su consciencia al respecto. Existe un amplio consenso entre los investigadores que han hecho del cine su objeto de estudio, a la hora de determinar $\mathrm{su}$ potencial como medio de comunicación social que ejerce distintas influencias sobre sus espectadores. Posiblemente, uno de los efectos más nocivos de las relaciones de pareja no igualitarias sea la violencia de género. En este sentido, existen varios trabajos que han analizado las relaciones entre el cine romántico y la violencia de género (Ferrer y Bosch, 2013; Aguilar, 2010). 
En el caso del cine de género romántico, existen una serie de premisas y características que, con bastante frecuencia, aparecen en distintos films: roles y estereotipos de género, relaciones de pareja idílicas, valores patriarcales, etc. Pero también se ha constatado con los distintos actores sociales implicados en la investigación, así como con el análisis fílmico, que se ha producido una evolución en parte de la producción cinematográfica más reciente hacia otros patrones como relaciones de pareja más igualitarias, perfiles de hombres $y$ mujeres alejados de los roles clásicos, o relaciones no heteronormativas, entre otros. En definitiva, existe una convivencia de relaciones de pareja tradicionales con otras alternativas, a veces incluso dentro del mismo film. Según los resultados alcanzados, los modelos puros no son los más frecuentes, sino que los patrones de comportamiento que encajan en nuestra configuración de modelo tradicional de relaciones de pareja, se han visto desdibujados en varios films por elementos del modelo alternativo $\mathrm{y}$ viceversa. Esto parece apuntar hacia unos roles y estereotipos de género que se van diluyendo progresivamente. A pesar de ello, la revisión de los 20 films nos ha conducido a la idea de que los cimientos que sostienen las relaciones de pareja en culturas occidentales siguen siendo sólidos, esto es, la pareja como centro de la vida cotidiana, la heteronormatividad, la relevancia del atractivo sexual, la complementariedad de la personas adecuada y la estabilidad de la pareja vinculada al matrimonio

A pesar de esta evolución que muestra nuevos derroteros por los que pueda discurrir parte del cine en los próximos años, aún hay que desterrar de la gran pantalla patrones de hombres y mujeres que se presentan como ideales buscando la identificación de su público, basándose en esquemas estereotipados y cuyas escenas muestran claros ejemplos de micromachismos. Lo que no está tan claro es si los guionistas y las productoras, como colectivo, seguirán avanzando hacia un reflejo de relaciones más igualitarias, o seguirán ralentizando los cambios que la sociedad actual demanda. Mientras esto ocurre, resulta alentador que los universitarios que cursan titulaciones vinculadas al ámbito educativo y de la comunicación reflejen actitudes críticas ante lo que el cine muestra. Los primeros podrán incorporar el cine como estrategia didáctica en las aulas para mostrar, por un lado, películas que apuesten por la igualdad entre hombres y mujeres $\mathrm{y}$, por otro, para 
fomentar un espíritu de reflexión y denuncia ante aquellas que muestran justo lo contrario. Los que se dedicarán al ámbito de la comunicación, podrán incorporar mayor realismo y sensibilidad en el ejercicio de su profesión, a la hora de abordar cuestiones como las relaciones de pareja.

En definitiva, este trabajo pone de relieve el potencial del cine como herramienta que favorece la transmisión de actitudes y valores. En el objeto de estudio que nos ocupa, el análisis de las relaciones de pareja, los vínculos son mostrados en el cine a veces desde una perspectiva igualitaria y otras, desde una óptica tradicional aderezada con estereotipos y roles de género. Por tanto, es preciso seguir profundizando $\mathrm{y}$ reflexionando sobre las líneas discursivas que el cine refleja y, en esta tarea, el ámbito educativo parece estar llamado a cobrar un mayor protagonismo. Se abre por tanto, una línea de investigación en la que habrá que seguir profundizando. Varios autores ya han abordado esta estela educativa desde el cine tanto en un ámbito general (Llamas, 2017) como de forma específica aplicada a ámbitos como violencia de género (Dussel, 2014). Como se ha mostrado en este artículo, el cine de género romántico tiene una serie de características que hacen que sus contenidos tengan como piedra angular las relaciones de pareja, convirtiéndolo en un punto de partida ineludible para abordar la igualdad de géneros en el ámbito cinematográfico.

\section{REFERENCIAS}

Aguilar, Pilar (2010), "El cine, una mirada cómplice en la violencia contra las mujeres.", en El sustrato cultural de la violencia de género, Madrid: Síntesis, 241-276.

Almacellas, María Ángeles (2004), Educar con el cine. Madrid: Ediciones Internacionales Universitarias.

Argote, Rosabel (2003), "La mujer inmigrante en el cine español del inaugurado siglo XXI.", Feminismo/s, 2, 121-138

Ballesteros, Isolina (1999), "Mujer y Nación en el cine español de posguerra: Los años 40.", Arizona Journal of Hispanic Cultural Studies, 3, 51-70.

Castro García, Amanda (2009), La representación de la mujer en el cine español de la Transición: (1973-1982). Oviedo: KRK Ediciones 
Charkow, W.B. y Nelson, E.S. (2000),

Relationship dependency, dating violence and scripts of female, Journal of College Counselling, 3(1), 12-17.

Cowie, Elisabeth (1997), Representing the woman: cinema and psychoanalysis. Basingstoke: Macmillan.

Dussel, Inés (2014), "Usos del cine en la escuela: una experiencia atravesada por la visualidad (The relationships between film and schooling: an experience crossed by visuality)", Estudos da Língua (gem) 12 (1), 77.

Esteban, Mari Luz (2011), Crítica del pensamiento amoroso: Temas contemporáneos. Barcelona: Edicions Bellaterra, S. L.

Ferrer Pérez, Victoria y Bosch Fiol, Esperanza (2013), "Del amor romántico a la violencia de género. Para una coeducación emocional en la agenda educativa.", Revista de curriculum y formación del profesorado, 17 (1), 105122. Consultado el 15.04.2017 en http://www.ugr.es/ recfpro/rev171ART 7.pdf
Giddens, Anthony (1991), Sociología.

Madrid: Alianza.

Gómez, Asunción (2002), "La representación de la mujer en el cine español de los años 40 y 50: del cine bélico al neorrealismo.", Bulletin of Spanish Studies, 79 (5), 575-589

Gómez, Carlos Moreno (2017), "Cine y Salud: Una estrategia audiovisual en la educación saludable con adolescentes.", Forum Aragón, 20, 1519

Gordillo Álvarez, Inmaculada (2007), "El diálogo intercultural en el cine español contemporáneo: entre el estereotipo y el etnocentrismo.", Revista Internacional de Comunicación Audiovisual, Publicidad y Literatura, 1 (4), 207-222.

Guarinos, Virginia (2008), "Mujer en Constitución: la mujer española en el cine de la Transición.", Quaderns de cine, $2,51-62$

Illouz, Eva (2009), El consumo de la utopía romántica: El amor y las contradicciones culturales del capitalismo. Madrid: Katz Editores. 
Illouz, Eva (2012), Por qué duele el amor: una explicación sociológica.

Madrid: Katz Editores.

Kaplan, Ann (1997), Representing the

Woman: Psychoanalysis and Cinema. London: Macmillan.

Lapsley, Robert and Westlake, Michael (1992), "From Casablanca to Pretty Woman: the politics of romance.", Screen, 33 (1), 27-49.

Lema, Eva Victoria y Vigil, María Dolores (2003), Los modelos de género masculino y femenino en el cine de Hollywood, 1990 - 2000. Madrid: Universidad Complutense.

Liles, Ray (2007), “The Use of Feature Films as Teaching Tools in Social Work Education.", Journal of Teaching in Social Work, 27 (3-4), 45-60. doi: 10.1300/J067v27n03_04

Llamas, Manuel González-Sicilia et al. (2016), Películas para la educación. Aprender viendo cine, aprender a ver cine. Madrid: Ediciones Cátedra.

Loscertales, Felicidad y Núñez, Trinidad (2001), Violencia en las aulas. El cine como espejo social. Barcelona:

Octaedro

Mangot, Ajish and Vasantmeghna Murthy (2017), "Cinema: A multimodal and integrative medium for education and therapy." Annals of Indian Psychiatry, 1 $51-53$

DOI: 10.4103/aip.aip_13_17

Martínez-Salanova, Enrique (2002), Aprender con el cine, aprender de película. Una visión didáctica para aprender e investigar con el cine. Huelva: Grupo Comunicar

Morales, Noelia (2017), "Las TIC y los escolares del medio rural, entre la brecha digital y la educación inclusiva", Bordón. Revista de pedagogía, 69 (3), 41-56.

DOI: https://doi.org/10.13042/Bordon.2 017.52401

Neale, Steve (1992), The big romance or Something Wild?: romantic comedy today, Screen, 33 (3), 284-299

Onfray, Michel (2002), Teoría del cuerpo enamorado. Por una erótica solar. Valencia: pre-textos. Consultado el 04.05 .2016 en 
Pascual Fernández, Alicia (2016),

"Sobre el mito del amor romántico.

Amores cinematográficos y educación."

Revista de educación y humanidades, 10 ,

63-78 Consultado el 12.01.2017

en http://hdl.handle.net/10481/41940.

Pereira, $\mathrm{M}^{\mathrm{a}}$ Carmen y Marín, $\mathrm{M}^{\mathrm{a}}$ Victoria (2001)," Respuestas docentes sobre el cine como propuesta pedagógica. Análisis de la situación en Educación Secundaria”, Teoría de la Educación. Revista Interuniversitaria, 13, 233-255.
Rodowick, David (1991), The Difficulty of Difference: Psychoanalysis, Sexual Difference and Film Theory. New York: Routledge

Sell Trujillo, Lucía et al. (2014), "El cine como herramienta educativa para abordar la violencia en las aulas.", PíxelBit. Revista de Medios y Educación, 45, 111-124. Consultado el 13.03.2017 en http://www.redalyc.org/html/368/36831 300008/

\section{Anexos}

Tabla 10. El cine refleja una realidad social sesgada, tergiversada.

\begin{tabular}{|l|l|l|l|}
\hline & Valor & gl & Sig. asintótica (bilateral) \\
\hline Chi-cuadrado de Pearson & 21,066 & 3 & $\mathbf{0 0 0}$ \\
\hline Razón de verosimilitudes & 16,824 & 3 &, 001 \\
\hline $\begin{array}{l}\text { Asociación lineal por } \\
\text { lineal }\end{array}$ & 11,878 & 1 &, 001 \\
\hline N de casos válidos & 247 & & \\
\hline
\end{tabular}

Tabla 11. Identificación con personajes del cine.

\begin{tabular}{|l|l|l|l|}
\hline & Valor & gl & Sig. asintótica (bilateral) \\
\hline Chi-cuadrado de Pearson & 11,994 & 3 & $\mathbf{, 0 0 7}$ \\
\hline Razón de verosimilitudes & 10,850 & 3 &, 013 \\
\hline $\begin{array}{l}\text { Asociación lineal por } \\
\text { lineal }\end{array}$ & 1,467 & 1 &, 226 \\
\hline \begin{tabular}{l} 
N de casos válidos \\
\hline
\end{tabular} & 249 & & \\
\hline
\end{tabular}

